\title{
Natural Product Synthesis via Biocatalysis: An Essay on the Merits of Multidisciplinary Ventures
}

\author{
Tomas Hudlicky \\ Chemistry Department, University of Florida, Gainesville, FL 32611, USA
}

Received: August 10, 1998

\begin{abstract}
Apresenta-se uma opinião crítica a respeito dos méritos de atividades multidisciplinares contendo uma certa dose de ousadia, em química orgânica sintética. Em particular, o conceito de "caixa-de-ferramentas" das metodologias disponíveis para a solução eficaz de problemas em síntese orgânica é analisado no contexto de exempolos disponíveis na literatura, assim como a partir e projetos de pesquisas em andamento em nosso grupo de pesquisas. A discussão de diversos casos de sínteses totais realizadas recentemente oferece evidências de que a introdução de métodos biocatalíticos melhora significativamente o processo global de preparação das substâncias alvo de uma síntese. Alguns exemplos desses projetos fomam igualmente o tópico da plenária deste autor no $8^{\circ}$ Encontro Brasileiro de Síntese Orgânica em Setembro de 1998.
\end{abstract}

A critical opinion is advanced on the merits of multidisciplinary ventures in synthetic organic chemistry. In particular, the concept of a "tool box" of methodologies available for effective solutions to problems in organic synthesis is analyzed in the context of available examples from the literature as well as from the ongoing projects in our research group. The discussion of several cases of recently accomplished total syntheses offers evidence that the introduction of biocatalytic methods greatly improves the overall process of preparation of target compounds. Some examples of such projects form also the topic of the authors lecture at the $8^{\text {th }}$ Brazilian Meeting on Organic Synthesis in September 1998.

Keywords: biocatalysis, natural synthesis

\section{Introduction}

The total synthesis of natural products enjoyed fast growth during the 1960's and the 1970's, perhaps at the expense of more basic disciplines such as physical organic chemistry and methodology-oriented synthetic organic chemistry. In the 1980's the emphasis returned to developmental organic chemistry. The reasons for such a paradigm shift are not entirely clear but there are several possible explanation: first, the trust in the synthetic community has been eroded because the promises of "practical solutions to the supply problem of therapeutically useful agents" have not materialized and no naturally occuring compound has been made by total synthesis in a manner competitive with isolation or fermentation methods. Second, the academic community shifted its emphasis to more methods-oriented investigations with focus on highly specific reagent-based solutions to uniquely defined problems in reaction development. Third, the community of synthetic chemists re- acted to critique from a defensive standpoint and instead of broadening its repertoir of methods for problem solving it focused even more narrowly on "classical" solutions to reaction control. It would therefore appear that the modern organic chemists have regressed rather than advanced in their pursuit of important problems in synthesis. The focus today is almost entirely on specific applications of reagents or reactions with a high degree of "local" control (i.e., diastereoselectivity) but of little use (as a concept) for wider audiences.

Some views supporting the above observations have already been recorded in the printed forum ${ }^{1-5}$. The accomplishments provided by modern synthetic ventures have been reviewed on a number of occasions with different conclusions. Certainly it would appear that organic synthesis is not a mature discipline, nor is it one in which the success of prediction of events approaches that of their explanation after the fact. Organic synthesis, unlike physics 
or engineering, is not built on irrefutable laws and depends to a great extent on serendipity, intuition, and observation. It is also clear that excursions beyond the traditional discipline of one's training bring about a great improvement in the problem solving process. Examples of such improvements are visible in the merging of inorganic and organic chemistry for catalyst development, molecular modeling in structure-activity research, and the combination of biology and chemistry for understanding the mode of action of drugs. What has not yet taken place is a fully accepted merger of biology and synthetic organic chemistry, although fermentation or partial fermentation approaches to target compounds are a way of life in the pharmaceutical industry. The academic community, certainly in the U.S. more so than in Europe, has been reluctant to accept the discipline of biocatalysis and continues to emphasize the traditional approaches to reaction control, which do not (and cannot) lead to efficient preparation of target compounds. The examples provided in this article should serve to convince the reader that biocatalytic synthesis offers unparallelled advantages over classical methods.

\section{Discussion}

Nature does not use many reactions or even many elements to control the outcome of a particular synthesis in the living systems. Metabolic processes rely instead on the precise definition of the environment in which a very simple reaction takes place (i.e., "substrate control"). The proteins that have evolved to recognize chemical substances for further functionalization do so with remarkable specificity and efficiency, unmatched by modern chemical methods. Their effectiveness stems entirely from controlling the orientation of the substrate (steric control) and not from recognizing the nature of the group to be transformed (electronic control). This point seems to be lost on the present-day organic chemist who frequently attempts exactly the opposite approach in the design of new reagents or catalysts.

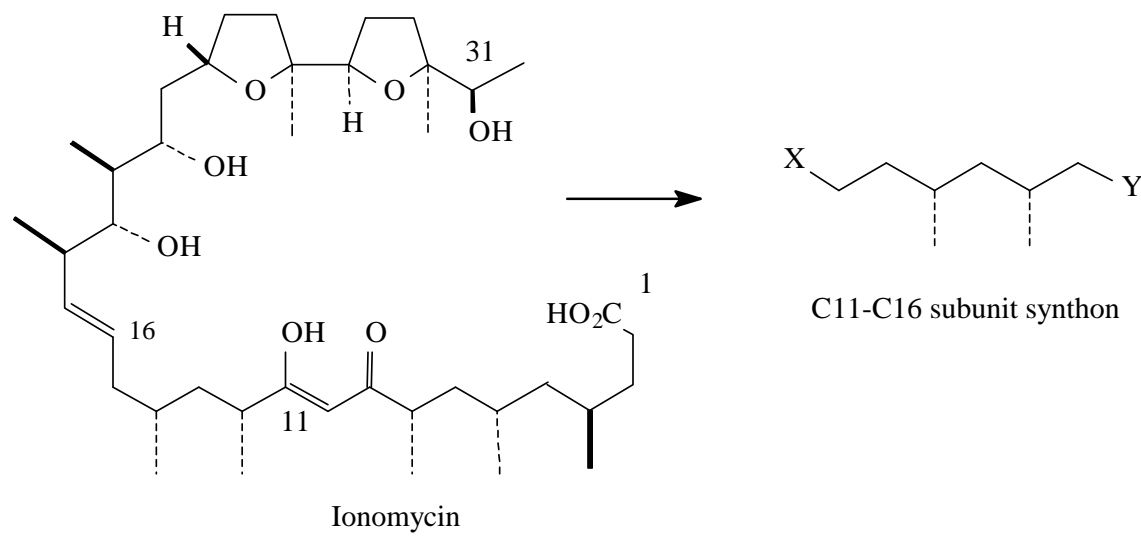

The mechanisms of many enzymatic reactions are relatively well understood, and there is ample technique available in molecular biology to express and even alter the function of many enzymes. Today the organic chemist should view these proteins simply as reagents for certain transformations to be incorporated into the planned pathway. It is remarkable how few academic groups (especially within the U.S.) have been open-minded to such combinations of disciplines. The following examples from the literature illustrate what happens to the overall effectiveness of a synthesis upon incorporating a single enzymatic step into the sequence of events.

A striking example of the increased efficiency that results when a new technology is incorporated into synthetic undertaking is seen in three approaches to the C11C16 subunit of ionomycin, Fig. 1. The synthesis of this subunit requires a solution to one of the classical problems in synthesis-controlling of stereochemistry at saturated centers on an acyclic framework. Taschner has recognized, quite brilliantly, that the relationship of the two methyl substituents corresponds to the cis-stereochemistry found in a cyclic meso ketone which may undergo enzymatic desymmetrization through the Baeyer-Villiger reaction ${ }^{6}$. Here, the use of either whole-cell fermentation or the isolated and purified enzyme (with the necessary cofactor recycling loop incorporated into the transformation) leads in four steps to the required synthon in an excellent overall yield, as shown in Fig. 2. By comparison, the classical approaches used by Evans ${ }^{7}$ and Hanessian ${ }^{8}$, shown in Fig. 3 , use many more steps to either establish (Evans) or manipulate (Hanessian) chirality at the onset of the synthesis. It is clear that the combination of the enzymatic step with standard chemical procedures yields a far more efficient (and, by definition, also less costly) preparation of the target compound.

On the other hand, one may argue that the purpose of the acadamician is to train new personnel, and thus the longer the synthesis, the more reactions the student can learn. Nevertheless, the training must also teach a realistic

Figure 1. Ionomycin and its subunit containing saturated stereogenic centers. 
Taschner (1991)

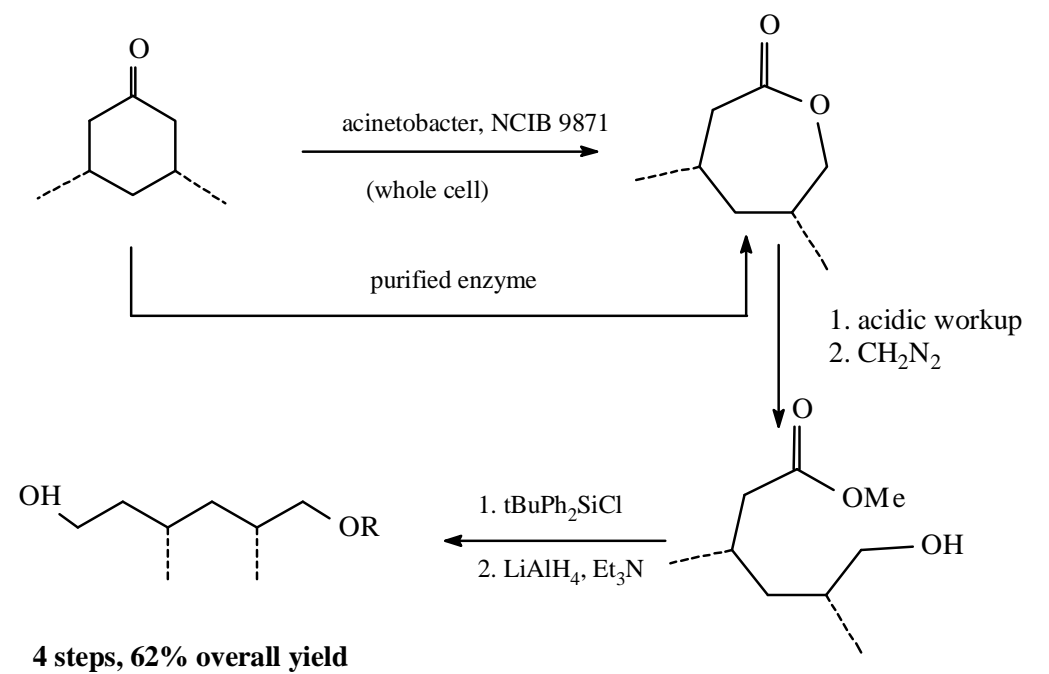

Figure 2. Taschners synthesis of the ionomycin subunit.

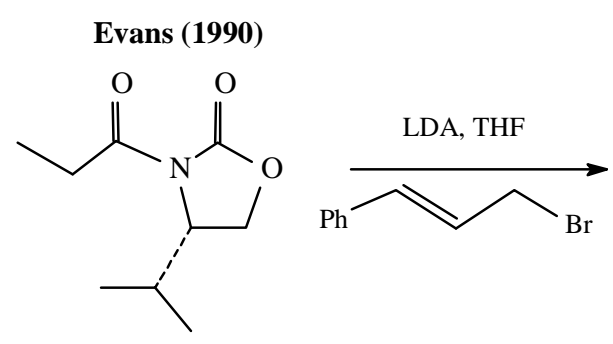

Hanessian (1986)

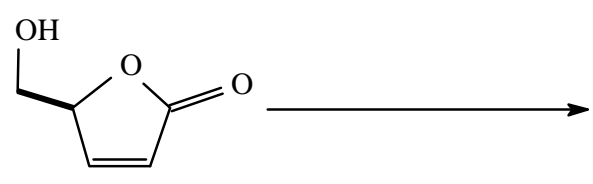

(from glucose)

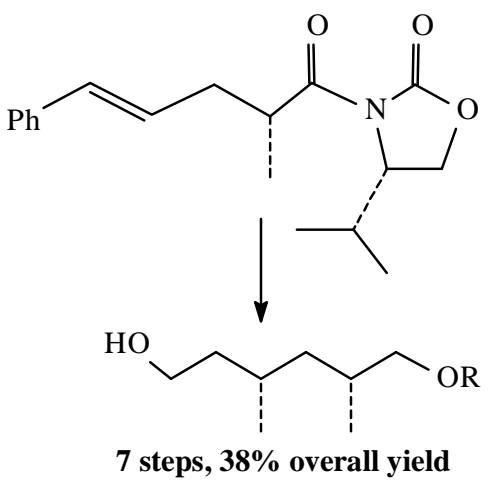

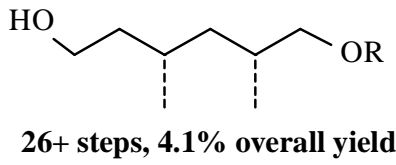

Figure 3. The synthesis of ionomycin subunit by Evans and by Hanessian.

view of the undertaking, its overall cost, permanent or even current value to society, and, above all, common sense. Unfortunately, many programs completely ignore the latter aspects of training and the result is a narrowly focused and ineffective delivery of the targets in insufficient amounts. Seldom does the academic community subject lengthy total syntheses to the ultimate test of reproducibility of both the preparation and the values of the reported yields. Only Organic Synthesis requires checking of the procedures by independent laboratories; other journals simply publish the results, validated by editors and referees who do not often question the authors' yield values even though they may find them unusually high. The "yield inflation" has emerged as a problem in the last twenty years or so and its continuous practice further detracts from the respect of synthesis in those instances where the reported products may have a real value in society ${ }^{2}$.

In some instances, the pursuit of a "new methodology"justifies the total synthesis, as in the example of a conduritol C synthesis, shown in Fig. 4. In Weinreb's approach, a vinyl silane-aldehyde cyclization is tested as means of carbon-carbon bond formation ${ }^{9}$. The pursuit of such methodology is, of course, noble, provided it results in a permanent enhancement of current technology. Here, 
however, the cyclization is non-selective, and the application to total synthesis somewhat forced, if one considers that the chirality in the target was supplied from the starting sugar. The synthesis of the methylated derivative of conduritol $\mathrm{C}$ thus requires 11 steps, as shown. By contrast, the recognition of enzymatic oxygenation of aromatics ${ }^{10}$ as a "tool" to establish permanently the cis-diol features within the product leads to a four-step preparation of the target compound in a manner that would lend itself to a largescale synthesis if desirable ${ }^{11}$.
Similarly, the features of the cis-diol in lycoricidine were recognized in the context of enzymatic methods of oxygenation and led to a very efficient synthesis of the desired target as portrayed in Fig. 5. In the approach by Chida, Ohtsuka and Ogawa only one of the chiral centers in glucose (C4) has been unchanged in the final target. The azido conduritol intermediate, acquired in 14 steps from glucose, contains the configuration corresponding to the diastereomer of conduramine A. The completion of the total synthesis of lycoricidine therefore requires a Mitsunobu inversion to adjust the stereochemistry of the alkaloid,

\section{Weinreb (1991)}

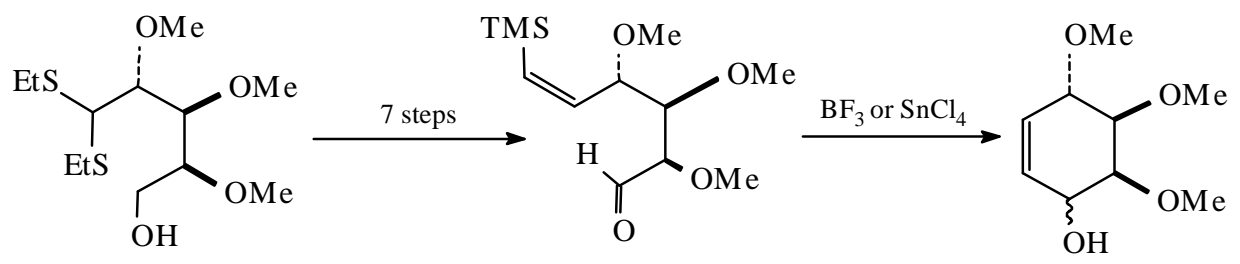

(3 steps from L-arabinose) $\quad 11$ steps, $10 \%$ overall yield<smiles>CC(C)(C)C1C=C(O)C(O)C(O)C1O</smiles>

4 steps, $41 \%$ overall yield

Figure 4. Comparison of conduritol $\mathrm{C}$ syntheses.<smiles>COC1OC(CBr)C(O)C(O)C1[N]</smiles>

7 steps from glucose<smiles>[R]OC1C([R2])C=CC([N])C1[R2]</smiles>

22 steps, $0.042 \%$ overall yield

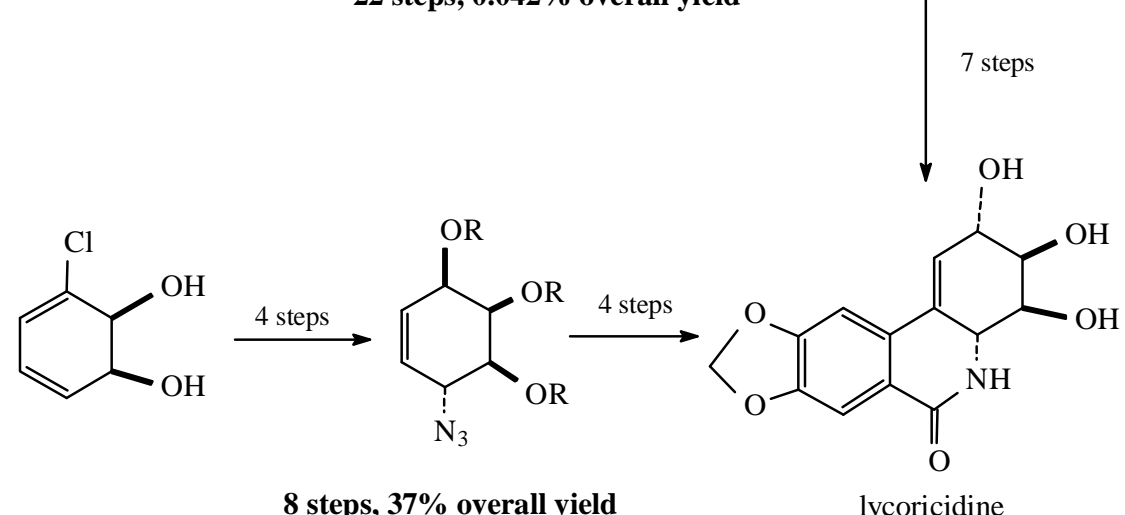

8 steps, $37 \%$ overall yield

lycoricidine

Figure 5. Comparison of lycoricidine syntheses. 
Wong (1993)

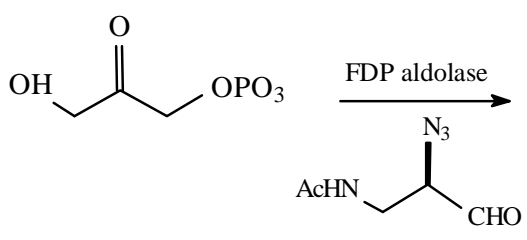<smiles>CCCCC(C)C(N)C(O)C(O)C(=O)CO</smiles>

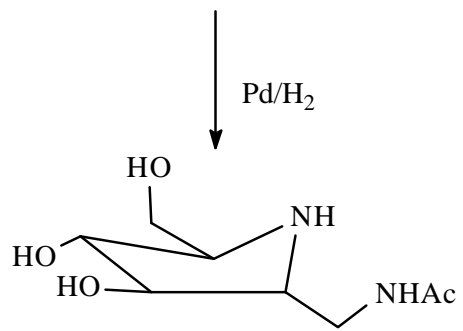

Figure 6. Design of aza sugar derivatives.

as shown ${ }^{12}$. By contrast, the dihydroxylation of chlorobenzene performed by toluene dioxygenase, coupled a stereospecific hetero-Diels-Alder reaction, sets all of the stereogenic centers correctly in just four steps. As in the former synthesis, the Heck reaction establishes the styrene unit in the final product ${ }^{13}$. The difference between the yields of these two preparation is staggering, Fig. 5.

An example that stands out as an exceptional demonstration of efficiency is Wong's preparation of the aza sugar derivative ${ }^{14}$, shown in Fig. 6. In this instance one of four diastereoselective aldolases has been used to achieve a particular configuration in the product. (The use of other aldolases results in specific generation of the other diastereomers of the product). The brevity of this approach is far superior to that of traditional preparations which relied on manipulations of available sugar derivatives.

These examples demonstrate the power of multidisciplinary solutions to a given problem. There are, of course, other means by which efficiency can be achieved: among these are incorporation of tandem reactions or cascades into the synthetic plan $^{15}$, as demonstrated for example by Majetichs perovskone synthesis ${ }^{16}$. In addition, one can carefully plan the sequence of the reactions in a "functionally redundant" manner, so that all the possible reaction pathways converge to one product, regardless of their order (see Ref. 2 for a definition and discussion of this term). Beautiful demonstrations of the latter principle are found in Heathcocks lycopodine ${ }^{17}$ and daphnilolactone ${ }^{18}$ syntheses, Wender's isocomene preparation ${ }^{19}$, and Hudlicky's pancratistatin synthesis ${ }^{20}$. Brevity - whether achieved by efficient design, choice of conditions, combination of methodologies, or advances in engineering of the reaction conditions - is the ultimate objective of a synthetic venture. The chemist will therefore obtain the best results with the use of well-equipped "tool box" of technologies available for effective problem solving.

\section{Conclusion}

Ideally, a complex molecule is synthesized in an efficient manner, at low overall cost, with incorporation of a truly innovative methodology or the use of truly novel means, and, at the same time, the entire process of its preparation serves the purpose of education for the junior members of the profession. In addition, the completed synthesis should elicit admiration of those chemists sensitive to perceptions of synthesis as an art form. A discourse on this topic is available ${ }^{2}$, and it is this author's continuous quest to see just how close to the ideal situation he can get. In our own approaches to natural products continuous refinements are made through multi-generation design in order to attend to some of the principles delineated in this article. It is hoped that the comparisons of the synthetic accomplishments above are taken as a guide for the readers own forays into total synthesis. Under no circumstances are these comparisons made to reflect on their designers' abilities as chemists. The words of this authors doctoral mentor, Professor Ernest Wenkert, come to mind in this connection: "...one may criticize chemistry at will but never the chemist...". I am grateful for this insight and hope that it continues to be propagated throughout the community in order that all of us achieve further improvements.

\section{References}

1.Seebach, D. Angew. Chem. Int. Ed. Engl. 1990, 29, 1320.

2. Hudlicky, T. Chem. Rev. 1996, 96, 3.

3. Cornforth, J.W. Aldrichim. Acta 1994, 27, 71.

4. Wender, P.A.; Miller, B.L. In Organic Synthesis: Theory and Applications; Hudlicky, T., Ed.; JAI Press: Greenwich, CT, 1993; Vol. 2, pp 27-66.

5. Hudlicky, T., Natchus, M.G. In Organic Synthesis: Theory and Applications; Hudlicky, T., Ed.; JAI Press: Greenwich, CT, 1993; Vol. 2, pp 1-25. 
6. Taschner, M.J.; Chen, Q.-Z. Bioorg. Med. Chem. Lett. 1991, 1, 535.

7.Evans, D.A.; Dow, R.L.; Shih, T.L.; Takacs, J.M.; Zahler, R. J. Am. Chem. Soc. 1990, 112, 5290.

8. Hanessian, S.; Murray, P.J. J. Can. Chem. 1986, 64, 2231.

9. McIntosh, M.C.; Weinreb, S.M. J. Org. Chem. 1991, $56,5010$.

10. For a review of this methodology see: Hudlicky, T.; Reed, J.W. In Advances in Asymmetric Synthesis; Hassner, A., Ed.; JAI Press: Greenwich, CT, 1995; Vol. 1, p 271.

11. Hudlicky, T.; Rulin, F.; Tsunoda, T.; Luna, H.; Andersen, C.; Price, J. D. Isr. J. Chem. 1991, 31, 229.

12. Chida, N.; Ohtsuka, M.; Ogawa, S. Tetrahedron Lett. 1991, 32, 4225 .
13. Hudlicky, T.; Olivo, H.F. J. Am. Chem. Soc. 1992 , $114,9694$.

14. Takaoka, Y.; Kajimoto, T.; Wong, C.H. J. Org. Chem. 1993, 58, 4809.

15. Tietze, L.F.; Beifuss, U. Angew. Chem. Int. Ed. Engl. 1993, 32, 131.

16. Majetich, G.; Zhang, Y. J. Am. Chem. Soc. 1994, 116, 4979.

17. Heathcock, C.H.; Kleinman, E.; Binkley, E.S. J. Am. Chem. Soc. 1978, 110, 8036; ibid. 1982, 104, 1054.

18. Heathcock, C.H.; Hansen, M.M.; Ruggeri, R.B.; Kath, J.C. J. Org. Chem. 1992, 57, 2544.

19. Wender, P.A.; Howbert, J.J. J. Am. Chem. Soc. 1981, 103, 688.

20. Tian, X.; Hudlicky, T.; Konigsberger, K. J. Am. Chem. Soc. 1995, 117, 3643. 